2 Cole BC, Cassell GH. Mycoplasma infections as models of chronic joint inflammation. Arthritis Rheum 1979;22:1375-81.

${ }^{3}$ Manchee RJ, Taylor-Robinson D. Haemadsorption and haemagglutination by mycoplasmas. 7 Gen Microbiol 1968;50:465-78.

4 Razin S, Michmann J, Shimshani Z. The occurrence of mycoplasma (PPLO) in the oral cavity of dentulous and edentulous subjects. $F$ Dent Res $1964 ; \mathbf{4 3}: 402-5$.

${ }^{5}$ Webster ADB, Loewi G, Dourmashkin RD, et al. Polyarthritis in adults with hypogammaglobulinaemia and its rapid response to immunoglobulin treatment. $\mathrm{Br} \mathrm{Med} \mathcal{F} 1976$;i:1314-6.

(Accepted 23 November 1982)

Northwick Park Hospital and Clinical Research Centre, Harrow, Middlesex HA1 3UJ

A $\mathrm{K}$ L SO, MA, MRCP, medical registrar

P M FURR, FIMLS, chief technician

D TAYLOR-ROBINSON, MD, FRCPATH, consultant microbiologist

A D B WEBSTER, FRCP, consultant physician

Correspondence to: Dr A K L So.

\section{Prevalence and treatment of gall stones after gastric bypass surgery for morbid obesity}

Obesity and rapid weight loss predispose to the formation of gall stones. ${ }^{1}$ We have documented the prevalence of gall stones before and after gastric bypass surgery for morbid obesity.

\section{Subjects, methods, and results}

Seventy three obese patients underwent gastric bypass operations between March 1980 and January 1982. Their median age was 34 years (range 18-51) median weight $118 \mathrm{~kg}$ (range 93-165), and 71 were women. Patients were fasted for 12 hours before operation. At operation a proximal gastric pouch of between 50 and $100 \mathrm{ml}$ in volume was constructed, which was drained through a narrow stoma $(10-12 \mathrm{~mm})$ into a $40 \mathrm{~cm}$ Roux-en-Y segment of jejunum. Fourteen of the patients had already had their gall bladders removed, and 19 underwent cholecystectomy for gall stones at the time of the gastric bypass. The remaining 40 patients were found to have normal gall bladders both on oral cholecystography and on palpation at operation.

Gall bladder bile samples were taken from 13 of the 19 patients who had gall stones at the time of operation. The median cholesterol saturation index ${ }^{2}$ was 1.26 (range $1 \cdot 00-1 \cdot 64$ ), and eight of the 13 patients had cholesterol crystals present on microscopy of the fresh bile samples.

Of the 40 patients with a normal gall bladder, 27 had transhepatic aspiration of gall bladder bile at the time of surgery. The median cholesterol saturation index was $1 \cdot 18$ (range $0 \cdot 75-1 \cdot 48$ ) but cholesterol crystals were found in only one of the fresh bile samples. Thirty of the 40 patients were subjected to repeat oral cholecystography during follow up (median time 12 months; range 4-27). Ten of the 30 had developed gall stones (only one of these patients had taken oral contraceptives). In nine patients the stones were found within 14 months of operation. Only four patients had biliary type pain. All the stones were less than $0.5 \mathrm{~cm}$ diameter and radiolucent, and most floated on the contrast medium. Stone formers had the greater weight loss during the first nine months after surgery, but weight loss at 12 months was comparable between the two groups.

Two of the 10 patients with stones were observed but not treated, and their stones disappeared within nine months of discovery, as judged radiographically and by ultrasound. Eight patients were treated with oral chenodeoxycholic acid $750 \mathrm{mg} /$ day. Complete dissolution occurred in five of these, one after 11 months of treatment and the other four within seven months. The only complication of treatment was diarrhoea in one patient, which led to withdrawal of the drug after nine months. The other two patients were still undergoing treatment (four and six months).

\section{Comment}

The high incidence of gall stones in morbidly obese patients was confirmed in this study. Of the 73 patients, 33 had developed gall stones before surgery, and a further 10 (of the 30 who underwent cholecystography) developed gall stones after a gastric bypass operation. The only major difference identified between the postoperative stone formers and the non-stone formers was a greater early weight loss in the stone formers (table).

The reduction of oral intake and its diversion from the upper
Details of 30 patients who underwent oral cholecystography after gastric bypass operation

\begin{tabular}{|c|c|c|c|}
\hline & & $\begin{array}{l}\text { Gall stones } \\
\text { detected }\end{array}$ & $\begin{array}{l}\text { No gall stones } \\
\text { detected }\end{array}$ \\
\hline 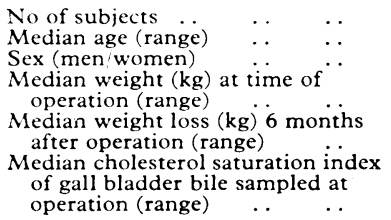 & $\begin{array}{l}\cdots \\
\cdots \\
\ldots\end{array}$ & $\begin{array}{c}10 \\
28(20-46) \\
0 / 10 \\
131(90-146) \\
39(25-57)^{*}\end{array}$ & $\begin{array}{c}20 \\
34 \begin{array}{c}(18-51) \\
2 / 18\end{array} \\
118(93-136) \\
31(9-39)^{*}\end{array}$ \\
\hline
\end{tabular}

${ }^{*} \mathrm{p}<0.01$ (Manu-Whitney U test, two tailed).

small bowel may reduce cholecystokinin release, resulting in stasis of gall bladder bile. This might facilitate the tendency for the supersaturated bile secreted during weight $\operatorname{loss}^{1}$ to nucleate and form cholesterol crystals (the proposed basis of gall stone formation).

Regardless of the mechanism of formation, the multiple small gall stones may disappear spontaneously or be amenable to dissolution by chenodeoxycholic acid. Because the cholesterol saturation index may return to normal once weight loss has stabilised, current policy is to observe stone formers for six months for spontaneous stone dissolution. Chenodeoxycholic acid is used only if stones persist after this period. This treatment might also be used as a prophylaxis against gall stone formation in these patients: Mok and colleagues ${ }^{3}$ showed that chenodeoxycholic acid reduces the cholesterol saturation index of bile when administered to obese patients during weight loss.

In conclusion we found that one third of patients investigated after gastric bypass surgery developed small radiolucent gall stones. Clinicians managing such patients should be aware that these stones may be transitory and are often amenable to dissolution treatment.

${ }^{1}$ Bennion LJ, Grundy SM. Risk factors for the development of cholelithiasis in man $N$ Engl 7 Med 1978;299:1161.

${ }^{2}$ Whiting MJ, Down RHL, Watts JMcK. Precision and accuracy in the measurement of the cholesterol saturation index of bile. Gastroenterology $1981 ; 80: 533$.

${ }^{3}$ Mok HYI, et al. Biliary lipid metabolism in obesity. Gastroenierology $1979 ; 76: 556$.

(Accepted 22 December 1982)

Flinders Medical Centre, Bedford Park, South Australia 5042

D A WATTCHOW, MB, BS, surgical registrar

J C HALL, FRACS, lecturer in surgery

M J WHITING, PHD, senior hospital scientist

B BRADLEY, BSC, research assistant

J IANNOS, BSC, technical officer

J MCK WATTS, FRACS, professor of surgery

\section{Acute urinary retention associated with sublingual buprenorphine}

Parenteral opiate analgesics have been shown to affect vesicourethral function, and intrathecal and epidural opiates reportedly precipitate acute urinary retention. ${ }^{1-3}$ There have been no reports of acute retention with buprenorphine given sublingually or via the epidural route. I report a case showing that buprenorphine (Temgesic) may precipitate acute retention of urine.

\section{Case report}

A 66 year old man with right sided T1 postherpetic neuralgia was prescribed sublingual buprenorphine by his general practitioner. After taking six $200 \mu \mathrm{g}$ tablets over 18 hours he developed acute urinary retention and was admitted as an emergency. He felt rather lightheaded but had noticed no other side effects. On arrival at hospital he voided a small amount of urine, catheterisation was postponed, and normal micturition was subsequently re-established without further intervention. He denied any previous urinary symptoms, especially those recognised as being associated with outflow obstruction-namely, hesitancy and a poor stream. ${ }^{4} \mathrm{He}$ had previously had a normal diurnal frequency and no nocturia.

Immediately after discharge from hospital the patient took a further two 
buprenorphine tablets and was again unable to void, on that occasion for 10 hours. He was referred for outpatient urodynamic assessment, which was performed four weeks after the initial episode. Results of medium fill (60 $\mathrm{ml} / \mathrm{min}$ ) filling and voiding cystometry were normal and urethral pressure profilometry (microtip transducer catheter) showed no evidence of a prostatic peak or plateau.

\section{Comment}

Buprenorphine is a synthetic opiate analogue which is thought to act at mu opiate receptors. In view of the known response of detrusor and urinary sphincters to opiate analgesics and the effects of the endogenous opioid peptides as deduced from studies of naloxone blockade ${ }^{5}$ it would be reasonable to suppose that buprenorphine should have similar effects. Probably further cases will be reported. In the interim I suggest that care should be taken in prescribing buprenorphine for patients with symptoms of urinary outflow obstruction.

Thanks are due to $\mathrm{Mr} \mathrm{J} \mathrm{C}$ Gingell for permission to report this case

' Doyle PT, Briscoe CE. The effects of drugs and anaesthetic agents on the urinary bladder and sphincters. Br f Urol 1976;48:329-35.

2 Barron DW, Strong JE. Postoperative analgesia in major orthopaedic surgery. Epidural and intrathecal opiates. Anaesthesia 1981 ;36:937-41.

3 Torda TA, Pybus DA, Liberman $\mathrm{H}$, et al. Experimental comparison of extradural and IM morphine. Br $\mathcal{F}$ Anaesth 1980;52:939-42.

4 Abrams PH, Feneley RCL. The significance of the symptoms associated with bladder outflow obstruction. Urol Int 1978;33:171-4.

${ }^{5}$ Murray KHA, Feneley RCL. Endorphins-a role in lower tract urinary tract function? The effect of opioid blockade on detrusor and urethral sphincter mechanisms. Br $\mathcal{F}$ Urol (in press).

(Accepted 20 December 1982)

Clinical Investigation Unit, Ham Green Hospital, Bristol KEITH MURRAY, MA, FRCS, research registrar in urology

\section{Hypercalcaemic sarcoidosis in hypoparathyroidism}

Increased plasma 1,25 -dihydroxy vitamin $\mathrm{D}$ concentration has been suggested as the possible cause of hypercalcaemia in sarcoidosis. ${ }^{12}$ Transient increase in dihydroxy vitamin $\mathrm{D}$ with hypercalcaemia has also been recorded in patients with hypoparathyroidism. ${ }^{3}$ Occasional reduction of vitamin $\mathrm{D}$ requirement after hypercalcaemia in treated hypoparathyroidism is well known. We report for the first time the association of sudden hypercalcaemia and a raised 1,25-dihydroxy vitamin $\mathrm{D}$ value with erythema nodosum developing in a patient with hypoparathyroidism.

\section{Case report}

A white woman born in 1952 had had epilepsy since the age of 5 which was moderately controlled with phenobarbitone. In 1971 hypocalcaemia $(1.6 \mathrm{mmol} / 1 ; 6.3 \mathrm{mg} / 100 \mathrm{ml})$ and hyperphosphataemia $(2.0 \mathrm{mmol} / 1 ; 6.1$ $\mathrm{mg} / 100 \mathrm{ml}$ ) were discovered, which responded to intravenous parathyroid extract. Plasma magnesium concentration, renal function, and histological findings in bone were normal. Idiopathic hypoparathyroidism was diagnosed and she subsequently required vitamin $D_{3} 1.5 \mathrm{mg}$ daily to maintain plasma calcium values in the low normal range. In 1976 she began phenytoin $100 \mathrm{mg}$ twice daily because of worsening epilepsy, and alfacalcidol was substituted for vitamin $\mathrm{D}_{3}$ to facilitate small adjustments of dosage; $3 \mu \mathrm{g}$ daily ultimately maintained low normal plasma calcium concentrations $(<2.4 \mathrm{mmol} / \mathrm{l}$; $<9.5 \mathrm{mg} / 100 \mathrm{ml}$ ) without calcium supplementation.

In October 1980 the patient presented with a six week history of tender red lumps on her legs and a two week history of thirst and polyuria. Examination showed typical erythema nodosum. Plasma calcium concentration (fig) was $3.2 \mathrm{mmol} / 1(12.8 \mathrm{mg} / 100 \mathrm{ml})$, chest radiography showed bilateral hilar lymphadenopathy, and a subsequent Kveim test gave an unequivocally positive result. Alfacalcidol was stopped and normocalcaemia was rapidly restored, though hypercalciuria $(8 \cdot 0-8 \cdot 5 \mathrm{mmol}(320-340 \mathrm{mg}) / 24 \mathrm{~h})$ remained after 10-11 days, the urine calcium value later falling to normal $(3 \cdot 0-4 \cdot 4$ mmol (120-176 mg)/24 h). Serum calcium concentration remained normal while erythema nodosum remained active, though a short course of hydrocortisone produced transient frank hypocalcaemia. Her alfacalcidol requirement was ultimately halved.

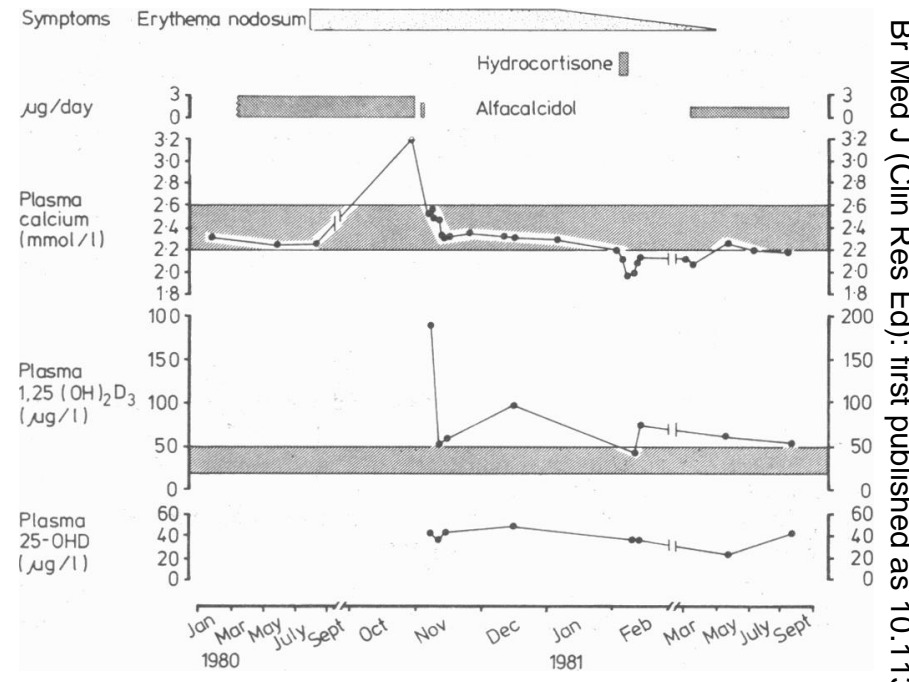

Symptoms, treatment, and serum calcium and plasma 25-hydroxy vitamin $\mathrm{D}$ (25-OHD) and 1,25-dihydroxy vitamin $\mathrm{D}_{3}\left(1,25(\mathrm{OH})_{2} \mathrm{D}_{3}\right)$ concentrations in relation to erythema nodosum developing in primary hypoparathyroidism. Note broken time scale. Symptoms shown declining after last appearance of new lesions. Serum calcium corrected for specific gravity; 1,25-dihydroxy $\infty$ vitamin $\mathrm{D}_{3}$ measured by radioimmunoassay. ${ }^{5}$ Hatched areas represent normal ranges.

Conversion: SI to traditional units-Calcium: $1 \mathrm{mmol} / 1 \approx 4 \mathrm{mg} / 100 \mathrm{ml}$.

\section{Comment}

Episodic increase in plasma 1,25-dihydroxy vitamin D concentration $\stackrel{\circ}{\supset}$ associated with hypercalcaemia has been described in treated hypo- $G$ parathyroidism,${ }^{3}$ pseudohypoparathyroidism, ${ }^{2}$ and sarcoidosis, ${ }^{1}$ 定 conditions characterised by absolute parathyroid deficiency, end organ resistance to parathyroid activity, and "functional hypopara- $\frac{\widehat{O}}{\partial}$ thyroidism," respectively. Pathological increase in dihydroxy vitamin $\overrightarrow{0}$ $\mathrm{D}$ may therefore occur independent of normal parathyroid regulation. One hypoparathyroid patient in this category had a non-caseating granuloma, ${ }^{3}$ though sarcoidosis was not mentioned. No other report has therefore documented hypercalcaemic sarcoidosis and raised 1,25-dihydroxy vitamin $\mathrm{D}$ values in hypoparathyroidism, nor have we $\bar{\partial}$ found record of sarcoidosis presenting with simultaneous erythema nodosum and hypercalcaemia.

Our patient had previously shown frank hypocalcaemia while $\stackrel{2}{\Rightarrow}$ taking $2 \mu \mathrm{g}$ alfacalcidol daily and had not had hypercalcaemia for $\overline{0}$ nine years (after temporarily increasing vitamin $\mathrm{D}_{3}$ to $2.0 \mathrm{mg}$ daily). 3 It therefore seems unlikely that erythema nodosum and simple intoxication coincided fortuitously, since 25 -hydroxy vitamin $\mathrm{D}$. concentrations were only at the top end of the normal range. We did not measure the plasma 1,25-dihydroxy vitamin D concentration during alfacalcidol treatment before hypercalcaemia. Nevertheless, the first recorded value of $190 \mathrm{ng} / \mathrm{l}$-though it was not measured until $\frac{0}{3}$ four days after stopping alfacalcidol-was over three times higher than the maximum previously reported among hypoparathyroid of patients receiving alfacalcidol 0.5 to $3.0 \mu \mathrm{g}$ daily. ${ }^{4}$ Moreover, dihydroxy vitamin $\mathrm{D}$ concentrations in our patient remained near or above the $\mathrm{O}$ upper limit of normal for several weeks. This raised value is therefore likely to have arisen from endogenous sources and not as a result of $\mathcal{O}$ alfacalcidol. Hypoparathyroidism is normally characterised by low $D$ dihydroxy vitamin D concentrations, ${ }^{4}$ and we conclude that our patient's raised values resulted from sarcoidosis. ${ }^{12}$ The relevance of $\tilde{N}$ any fall in value related to hypocalcaemia during corticosteroid $\mathrm{N}$ administration was uncertain.

Increased vitamin D sensitivity in hypoparathyroidism occasionally results after vitamin $\mathrm{D}$ intoxication. Our observations, with those toe date, ${ }^{3}$ are consistent with a view that both initial hypercalcaemia and $\frac{}{\Phi}$ subsequent lower vitamin D requirement may sometimes result from a cryptogenic increase in circulating 1,25-dihydroxy vitamin $\mathrm{D}$. How 0 often this may result from overt or covert sarcoidosis is a question for $\bar{O}$ further research.

We are grateful to Dr J L H O'Riordan for antibody used in the 1,25 - $\varrho$ dihydroxy vitamin $\mathrm{D}$ assays. Assays were performed with financial help from an MRC programme grant to Professor $S \mathrm{~W}$ Stanbury.

1 Papapoulos SE, Clemens TL, Fraher LJ, Lewin IG, Sandler LM L'Riordan JLH. 1,25-dihydroxycholecalciferol in the pathogenesis of the hypercalcaemia of sarcoidosis. Lancet 1979;i:627-30. . 